\title{
MATHEMATICAL SCIENCES INSTITUTE AT CORNELL UNIVERSITY
}

Cornell University established a Mathematical Sciences Institute in January 1986, under a contract with the U.S. Army Research Office. The objective of the Institute is to perform basic research in broad areas of applied mathematics, with potential applications to science and engineering. Professor Geoffrey S. S. Ludford is the Director of the Institute.

Statistics and applied probability is one of the four designated areas of research in the Institute, the other three being applied analysis, physical mathematics and numerical analysis. Professor N. U. Prabhu is the Program Coordinator for statistics and applied probability. The research program in this area emphasizes computational statistics, data analysis, reliability, quality control and stochastic processes.

The Institute's program will provide for the following:

Visitors. Each year the Institute will partially support a very substantial number of senior scientists for periods ranging from a few weeks to a few months. The Institute will award ten (10) post-doctoral fellowships every year over the four areas designated above. These awards will be made normally for a year, but are renewable for a second year.

Graduate Fellowships. Twenty (20) graduate fellowships will be awarded each year on the basis of open competition. To be eligible, a graduate student must be writing a thesis in one of the designated areas.

Workshops. The Institute will conduct at least two workshops in each area every year. Workshops will focus on a current area of research and participation will be limited.

Consulting. The Institute will provide technical assistance to the Army. Most of this assistance will be coordinated by the Statistical Consulting Service of the Cornell Statistics Center, and through a Supercomputing Liaison Unit that will work with the Cornell Theory Center. Visiting scientists and postdoctoral fellows may occasionally be called upon for help in answering specific technical questions.

During the first year the following members of the Cornell faculty in the area of statistics and probability will be affiliated with the Institute: Professors Robert E. Bechhofer, David C. Heath, Thomas J. Santner, Howard M. Taylor and Paul F. Velleman. Professor Walter L. Federer will be the Director of the Statistical Consulting Service.

For further information please write to Professor N. U. Prabhu, Program Coordinator for Statistics and Applied Probability, Mathematical Sciences Institute, Caldwell Hall, Cornell University, Ithaca, NY 14853; phone (607)256-4856. 


\section{Advances in Applied Probability}

The Editorial Board would like to encourage the submission to the Advances of review papers summarising and coordinating recent results in any of the fields of applied probability.

In addition to these review papers, Advances is also designed to be a medium of publication for (1) longer research papers in applied probability, which may include expository material, (2) expository papers on branches of mathematics of interest to probabilists, (3) papers outlining areas in the biological, physical, social and technological sciences in which probability models can be usefully developed, (4) papers in applied probability presented at conferences which do not publish their proceedings, and finally, (5) letters to the editor on any appropriate topic in applied probability.

In short, the main function of Advances is to define areas of recent progress and potential development in applied probability. As with the Journal of Applied Probability, Advances undertakes to publish papers accepted by the Editors within 15 months of their submission; letters to the editor will normally be published more rapidly.

The Editor-in-Chief is J. Gani; the Coordinating Editors are C. C. Heyde, M. F. Neuts and G. E. H. Reuter; other editors are P. J. Brockwell, V. R. Cane, J. W. Cohen, E. J. Hannan, J. Keilson, D. G. Kendall, J. F. C. Kingman, K. Krickeberg, R. M. Loynes, K. R. Parthasarathy, C. A. B. Smith, and R. L. Tweedie. The Editorial Office of the Advances is in the Department of Probability and Statistics, The University, Sheffield S3 7RH, England.

Volume 18 No. 2 of Advances contains the following papers:

FRANK BALL. A unified approach to the distribution of total size and total area under the trajectory of infectives in epidemic models

ROBERT P. KERTZ. Comparison of optimal value and constrained maxima expectations for independent random variables.

FREDERICK J. BEUTLER AND KEITH W. ROSS. Time-average optimal constrained semiMarkov decision processes

R. J. BHANSALI. A derivation of the information criteria for selecting autoregressive models M. F. SCHILLING. Mutual and shared neighbor probabilities: finite- and infinite-dimensional results

ALAN F. KARR. Inference for stationary random fields given Poisson samples

JAMES W. DROSEN. Pure jump shock models in reliability

GUY FAYOLLE, PHILIPPE FLAJOLET AND MICHA HOFRI. On a functional equation arising in the analysis of a protocol for a multi-access broadcast channel

F. P. KELLY. Blocking probabilities in large circuit-switched networks

ALAN WEISS. A new technique for analyzing large traffic systems

MARCEL F. NEUTS. A new informative embedded Markov renewal process for the $\mathrm{PH} / \mathrm{G} / 1$ queue

D. R. COX AND VALERIE ISHAM. The virtual waiting-time and related processes

Subscription rates (per volume) for the Advances in 1986 are the same as for the Journal (see inside back cover). A discount of $10 \%$ is allowed to subscribers who order current issues of both the Journal and Advances at the same time direct from the Applied Probability Office. A detailed price list for both current and back issues is available on request.

Cheques made out on U.S., U.K. and Australian banks will be acceptable: they should be made payable to Applied Probability, and sent to:

Executive Editor, Applied Probability,

Department of Probability and Statistics,

The University, Sheffield S3 7RH, England. 


\section{ESSAYS IN TIME SERIES AND ALLIED PROCESSES}

In January 1986 the Applied Probability Trust published a supplementary volume 23A of the Journal of Applied Probability (JAP) to mark the sixty-fifth birthday of Professor E. J. Hannan FAA, FASSA, an editor of the Journal since its inception in 1964. Entitled Essays in Time Series and Allied Processes, this book consists of papers relating to various aspects of time series, Professor Hannan's main area of research. The seven sections are devoted to: structure and general methods, estimation, hypothesis testing and distribution theory, non-linear and non-stationary systems, random fields and point processes, allied stochastic processes, and algorithms and computations.

This special volume, which is edited by J. Gani and M. B. Priestley, contains contributions from the following colleagues and students of Professor Hannan:
An Hong-Zhi
J. Henstridge
M. R. Osborne
G. K. Smyth
C. F. Ansley
S. M. Heravi
T. Ozaki
V. Solo
M. S. Bartlett
C. C. Heyde
E. Parzen
T. P. Speed
P. Bloomfield
Y. Hosoya
J. H. W. Penm
K. Tanaka
D. R. Brillinger
R. H. Jones
M. B. Priestley
R. D. Terrell
M. A. Cameron
K. Katsura
B. G. Quinn
P. J. Thomson
Chen Zhao-Guo
R. Kohn
J. Rissanen
P. Tin
M. Deistler
P. A. P. Moran
P. M. Robinson
J. G. Veitch
J. Durbin
D. F. Nicholls
M. Rosenblatt
G. S. Watson
J. Gani
Y. Ogata
R. Shibata
P. Whittle

A complete bibliography of Professor Hannan's publications from 1955 to 1984 is included.

Essays in Time Series and Allied Processes is in the usual JAP format $(250 \times 170 \mathrm{~mm})$ with 437 pages, but with hard binding and an attractive dust jacket. The price is $£ 30.00$ (US\$35.00; $\$ \mathrm{~A} .43 .00$ ).

Orders, preferably accompanied by a remittance, should be sent to the Executive Editor, Applied Probability, Department of Probability and Statistics, The University, Sheffield S3 7RH, England. Payments must be in favour of 'Applied Probability': sterling cheques should be drawn on a British bank, US or Australian dollar cheques on a US or Australian bank respectively. 


\section{ESSAYS IN STATISTICAL SCIENCE}

In 1982 the Applied Probability Trust issued a supplementary volume No. 19A of the Journal of Applied Probability (JAP). Entitled Essays in Statistical Science, this book consists of a collection of papers on a range of topics including statistical theory; stochastic processes, time series, geometric probability and mathematical genetics. It was published as a Festschrift in honour of the sixty-fifth birthday of Professor P. A. P. Moran FAA, FRS, of the Department of Statistics, Australian National University, Canberra, an editor of JAP from 1964 to 19.2 .

This special volume is edited by J. Gani and E. J. Hannan and contains contributions from the following colleagues and students of Professor Moran: M. S. Bartlett, B. Benjamin, V. Cane, H. Cohn, D. J. Daley, H. E. Daniels, A. W. Davis, P. Erdös, W. J. Ewens, P. D. Finch, J. Gani, J. M. Hammersley, E. J. Hannan, A. M. Hasofer, C. R. Heathcote, C. C. Heyde, D. G. Kendall, J. F. C. Kingman, R. McNamee, D. R. McNeil, R. J. Maillardet, R. E. Miles, B. H. Neumann, M. Osborne, D. K. Pickard, D. Pollard, B. C. Rennie, E. L. Scott, E. Seneta, C. A. B. Smith, D. Vere-Jones, I. Vincze, G. S. Watson, G. A. Watterson, M. Westcott, P. Whittle, E. J. Williams and S. R. Wilson.

Essays in Statistical Science is in the usual JAP format $(250 \times 170 \mathrm{~mm})$; with 434 pages, and has an attractive dust jacket and hard binding. The price is $£ 18.00$ (US\$26.00; \$A28.00). Orders should be sent to the Executive Editor, Applied Probability, Department of Probability and Statistics, The University, Sheffield S3 7RH, England. 


\title{
PERSPECTIVES IN PROBABILITY AND STATISTICS
}

\author{
Papers in honour of M. S. Bartlett on the occasion of his sixty-fifth birthday
}

\author{
Editor: J. GANI
}

\section{Contributors}

$\begin{array}{llll}\text { P. Armitage } & \text { H. Cramér } & \text { A. M. Kshirsagar } & \text { L. Takács } \\ \text { N. T. J. Bailey } & \text { H. E. Daniels } & \text { T. Lewis } & \text { P. Tautu } \\ \text { G. A. Barnard } & \text { J. Gani } & \text { P. D. M. Macdonald } & \text { D. Vere-Jones } \\ \text { A. Blanc-Lapierre } & \text { U. Grenander } & \text { P. Meier } & \text { P. Whittle } \\ \text { V. R. Cane } & \text { J. M. Hammersley } & \text { P. A. P. Moran } & \text { E. J. Williams } \\ \text { W. G. Cochran } & \text { E. J. Hannan } & \text { C. R. Rao } & \text { H. Wold } \\ \text { J. W. Cohen } & \text { D. G. Kendall } & \text { C. A. B. Smith } & \\ \text { D. R. Cox } & \text { J. F. C. Kingman } & \text { H. Solomon } & \end{array}$

Pp. viii +423

This book was published by the Applied Probability Trust in 1975 as a tribute to Professor Bartlett from colleagues throughout the world. Due to difficulties in storing the remaining stock, we are now making copies available to our readers and subscribers at only $£ 3.50$ (US\$5.00; $\$ A .6 .00$ ) to cover administrative costs, postage and packing. Please order your copy now from

\author{
Applied Probability Office, \\ Department of Probability and Statistics, \\ The University, \\ Sheffield S3 7RH, England.
}

Remittances to 'Applied Probability', please.

' $\ldots$. there is variety and imagination in this volume.... Through their enthusiasm and ingenuity these 30 authors have provided a fitting tribute to a master.'

David Hinkley in Science

'The text is a delight to read, and several of the papers are gems in their own right.... it contains many stimulating ideas for potential research students.'

\section{Eric Renshaw in British Book News}

'.... there are substantial original contributions and magisterial summaries of important areas of knowledge.... The volume is a pleasure to browse in. It has benefitted from careful editing and production.'

John Hajnal in JRSS A 


\section{ANNALS OF OPERATIONS RESEARCH}

Editor in chief:

Peter L. Hammer, RUTCOR - Rutgers Center for Operations Research, Hill Center for the Mathematical Sciences, Rutgers University, Busch Campus, New Brunswick, NJ 08903

\section{Editorial Board:}

J. Abadie, Paris; E. Balas, Pittsburg, PA; E.M.L. Beale, Milton Keynes; R.E. Burkard, Graz; D. de Werra, Lausanne; P.C. Fishburn, Murray Hill, NJ; M. Grigoriadis,

New Brunswick; P. Hansen, Mons; M. Iri, Tokyo; P. Kall, Zürich; B. Korte, Bonn; W.F. Lucas, Claremont, CA; H. Müller-Merbach, Kaiserslautern; G.L. Nemhauser, Ithaca, NY; A. Prekopa, Budapest; A.H.G. Rinnooy Kan, Rotterdam F.S. Roberts, New Brunswick, NJ; S.M. Robinson, Madison, WI; B. Rosen, Minneapolis, MN; M. Segal, Holmdel, NJ; B. Simeone, Rome; R. Wets, Lexington, KY

The Annals of Operations Research will publish a series of volumes dedicated to the presentation of the current level and of the main trends of the development of specific areas of the field.

Each volume will consist of original manuscripts, survey articles, selected and tested computer programs, etc. The Annals of Operations Research hope to play an active role in the publication of well-refereed Conference Proceedings or selected papers thereof and in publishing volumes of contributed papers in well defined areas of OR from highly theoretical to the algorithmic and also to the very applied.

Every volume will have one or more Guest Editors who will be personnally responsible for the collection of papers to appear in that volume, for the refereeing process and for the time schedule.

All papers will be subject to peer refereeing and there will be no page charge.

Available as journal edition and as separate hardbound volumes.

Publication schedule: 1984: vol. 1 \& 2. 1985: vol. 3 \& 4 . 1986: vol. 5, 6 and 7 .

\section{ISSN $0254-5330$}

Separate volumes, hardbound

vol. 1: Archetti \& Maffioli, Stochastics and Optimization. 1984. vol. 2: Thompson \& Thrall, Normative Analysis in Policy Decisions, Public and Private. 1985

vol. 3: Stecke \& Suri, Flexible Manufacturing Systems:

Operations Research Models and Applications. 1985.

vol. 4-5: Monma, Algorithms and Software for Optimization. 1985.

vol. 6: Osleeb \& Ratik, Locational Decisions: Methodology and Applications. 1986

vol. 7: Blazewicz, Cellary, Slowinski, and Weglarz, Scheduling under Resource Constraints - Deterministic Models. 1986.

vol. 8: Albin \& Harris, Statistical and Computational Problems in Probability Modeling. 1987.

Price per volume including postage: Sfr. 411.--/US\$ 152.50

Reduced price for ORSA/TIMS members: Sfr. 85.--/US\$ 42.50

Journal subcription, paperbound

vol. 5-7, 1986, Sfr. 377.--/US\$ 139.50 per vol. incl. postage

vol. 1-4, 1984-1985, Sfr. $411,--$ USS 152.50 per vol. incl. postage.

\section{QUEUEING SYSTEMS THEORY AND APPLICATIONS}

Editor-in-Chief:

N.U. Prabhu, 338 Upson Hall, Cornell University, Ithaca, NY 14853, U.S.A.

\section{Associate Editors:}

U.N. Bhat, Dallas, TX, USA; A.A. Borovkov, Novosibirsk, USSR; O.J. Boxma, Amsterdam, The Netherlands; P. Brémaud, Paris, France; J.A. Buzacott, Waterloo, Canada; K.M. Chandy, Austin, TX, USA; B.T. Doshi, Holmdel, NJ, USA; P. Franken, Berlin, GDR; C.M. Harris, Charlottesville, VA, USA; J. Hunter, Auckland, New Zealand; N.K. Jaiswal, New Delhi, India;

T. Rolski, Wroclow, Poland; M. Rubinovitch, Haifa, Iarael; R. Schassberger, Berlin, W.-Germany; R.F. Serfozo, Atlanta GA, USA; S. Stidham, Jr., Raleigh, NC, USA;

J.G.C. Templeton, Toronto, Canada; J. Walrand, Berkeley, CA, USA; W. Whitt, Holmdel, NJ, USA.

The journal will publish papers on the theory and applications of queueing systems. It will cover a broad spectrum of topics of current research on queueing systems, crossing existing boundaries of academic disciplines. Particularly welcome are papers on computer performance, communication systems, flexible manufacturing systems and transportation. Summaries of computational work and reports of case studies will be encouraged. There will be review articles and a section on short communications.

The Journal will be exacting and scholarly in its standards. Every effort will be made to promote innovation, vitality and communication between disciplines.

Our objective is to make QUESTA the definitive Journal on queueing systems, deserving of the loyalty of all researchers in theory and applications of these systems.

Forthcoming papers:

J.A. Buzacott and David D. Yao: On queueing network models of flexible manufacturing systems

Bharat T. Doshi: Queueing systems with vacations - a survey

Edward G. Coffman, Jr. and Micha Hoffri: Queueing analysis of secondary storage devices

U. Narayan Bhat and S. Subba Rao: Statistical analysis of queueing systems

Edward H. Lipper and Bhaskar Sengupta: Assembly-like queues with finite capacity: bounds, asymptotics and approximations

U. Narayan Bhat: Finite capacity assembly-like queues

Bhanu G. Bhaskaran: Almost sure convergence of birth and death processes with applications to $\mathrm{M} / \mathrm{M} / \mathrm{s}$ queueing systems

Volume 1, 4 issues, 1986, 400 pages, ISSN 0256-0130, Sfr. 304.00/US\$ 112.50 incl. postage. Special price for ORSA/TIMS members Sfr. 85.00/US\$ 42.50 incl. postage. 


\section{SUBSCRIPTION RATES}

Subscription rates (post free) for the 1986 volume of the Journal are as follows:

Subscribers in North, Central and South America, and Australia:

US\$96.00; $\$ A 120.00 ; £ 81.00$ for libraries and institutions;

US $\$ 32.00 ; \$ A 40.00 ; £ 27.00$ for individuals belonging $: 0$ a recognised scientific society.

All other subscribers:

$£ 66.00$ for libraries and institutions;

$£ 22.00$ for individuals belonging to a recognised scientific society.

Members of the London Mathematical Society should apply direct to the Secretary of the Society for copies of the Journal.

All enquiries about the Journal, as well as other subscriptions, should be sent to the Executive Editor, Miss M. Hitchcock, Department of Probability and Statistics, The University, Sheffield S3 7RH, England. The price of back numbers varies from volume to volume, and enquiries should be sent to the Executive Editor. Cheques, money orders, etc. should be made out to Applied Probability; cheques on U.S., U.K. and Australian banks will be acceptable.

\section{NOTES FOR CONTRIBUTORS}

Papers published in the Journal are of two kinds:

(1) research papers not exceeding 20 printed pages;

(2) short communications of a few printed pages in the nature of notes or brief accounts of work in progress.

Review papers, longer research papers and leiters to the editor are published in Advances in Applied Probability, a companion journal. (Note: Letters relating specifically to papers which have appeared in the Journal of Applied Probability will continue to appear in the Journal.)

The editors may publish accepted papers in either journal, according to the space available, in order to meet the 15-month deadline in publication referred to below.

\section{Submission of papers}

It is a condition of publication in the Journal of Applied Probability that papers shall not previously have appeared elsewhere, and will not be reprinted without the written permission of the Trust. It is the policy of the Journal not to accept for publication papers which cannot appear in print within 15 months of the date of receipt of the final version. Authors will receive 50 reprints of their papers free, and joint authors a proportional share of this number. Additional reprints will be provided at cost.

Papers should be written in English or French; papers in other languages may be accepted by the editors, but will appear (subject to the author's agreement) in English or French translation in the Journal. Scripts should be typewritten, using double spacing, and at least one copy should be on one side of the paper only. Each paper should be accompanied by

(i) a short abstract of approximately 4-10 lines giving a non-mathematical description of the subject matter and results;

(ii) a list of keywords detailing the contents for the purpose of computerised information retrieval.

Authors are advised to consult The Author's Guide to the Applied Probability Journals when preparing papers for submission. A copy of this guide may be obtained on application to the Applied Probability Office.

For efficiency in processing, authors are requested to send three copies of all submissions to the Applied Probability Office in Sheffield, rather than to individual editors. Authors overseas are asked to ensure that their submissions are sent by airmail. The Editor-in-Chief and the Applied Probability Office are in regular contact and full details of all papers submitted are available to Professor Gani at the University of California at Santa Barbara.

\section{Copyright}

The copyright of all published papers shall be vested in the Trust. When a paper is accepted for publication, the Trust requests the author(s) to sign a form assigning copyright to the Trust. Failure to do this promptly may delay or prevent publication.

Authorisation to photocopy items for internal or personal use, or the internal or personal use of specific clients, is granted by the Applied Probability Trust for libraries and other users registered with the Copyright Clearance Center (CCC) Transactional Reporting Service, provided that the base fee of $\$ 00.50$ per copy, plus .10 per page is paid directly to CCC, 27 Congress St., Salem, MA 01970, U.S.A. $0021-9002 / 86 \$ 00.50+.10$. 


\section{Volume 23 Number 2}

\section{Research Papers}

265 ANDERS MARTIN-LÖF. Symmetric sampling procedures, general epidemic processes and their threshold limit theorems

283 PETER DONNELLY. A genealogical approach to variable-population-size models in population genetics

297 REINHARD HÖPFNER. Some results on population-size-dependent Galton-Watson processes

307 A. M. KELLERER. The variance of a Poisson process of domains

322 JÜRG HÜSLER. On point processes on the circle

332 CHERN-CHING CHAO AND JOHN SLIVKA. Some exact distributions of a last one-sided exit time in the simple random walk

341 G. MAZZIOTTO. Approximations of the optimal stopping problem in partial observation

355 PAUL DEHEUVELS AND JOSEF STEINEBACH. Exact convergence rate of an Erdös-Rényi strong law for moving quantiles

370 P. L. DAVIES. Rates of convergence to the stationary distribution for $k$-dimensional diffusion processes

385 ENZO ORSINGHER. A planar random motion governed by the two-dimensional telegraph equation

398 V. GIORNO, A. G. NOBILE, L. M. RICCIARDI AND L. SACERDOTE. Some remarks on the Rayleigh process

409 A. THAVANESWAREN AND M. E. THOMPSON. Optimal estimation for semimartingales

418 DENNIS V. LINDLEY AND NOZER D. SINGPURWALLA. Multivariate distributions for the life lengths of components of a system sharing a common environment

432 TERJE AVEN AND BO BERGMAN. Optimal replacement times - a general set-up

443 MASAKIYO MIYAZAWA. Approximations of the queue-length distribution of an $M / G I / s$ queue by the basic equations

459 V. V. KALASHNIKOV AND S. T. RACHEV. Characterizations of inverse problems in queueing and their stability

474 J. GEORGE SHANTHIKUMAR AND DAVID D. YAO. The effect of increasing service rates in a closed queueing network

484 M. H. VAN HOORN AND L. P. SEELEN. Approximations for the $G I / G / c$ queue

495 BRUNO VISCOLANI. An adaptive multistage queueing system

\section{Short Communications}

504 N. C. WEBER. The Wright-Fisher model with varying selection

509 KIM-ANH DO AND HERBERT SOLOMON. A simulation study of Sylvester's problem in three dimensions

514 DROR ZUCKERMAN. Optimal stopping in a continuous search model

519 KYLE SIEGRIST. Markov chains with binomial time change

524 J. MICHAEL STEELE AND LUKE TIERNEY. Boundary domination and the distribution of the largest nearest-neighbor link in higher dimensions

529 R. J. MARTIN. A note on the asymptotic eigenvalues and eigenvectors of the dispersion matrix of a second-order stationary process on a $d$-dimensional lattice

536 TOSHIO NAKAGAWA. Periodic and sequential preventive maintenance policies

543 WILLIAM A. MASSEY. A family of bounds for the transient behavior of a Jackson network

550 ROBERT B. COOPER AND SHUN-CHEN NIU. Beneš's formula for $M / G / 1$-FIFO 'explained' by preemptive-resume LIFO

$555 \mathrm{R}$. SZEKLI. On the concavity of the waiting-time distribution in some $G I / G / 1$ queues

562 Correction

Published by the Applied Probability Trust in association with the London Mathematical Society (C) 1986 ISSN 0021-9002 